brickwork inside the furnace or fire-box, which are duly described by the author. The spray-injector is of course illustrated. On this depends the efficient working of the furnace. The oil is blown into the furnace by means of a steam jet. Experiments have been made on the use of compressed air instead of steam; and, from what could be observed during a two months' trial, the complication and cost of the extra gear would not be recouped by a sufficiert economy in fuel consumption. The effect of petroleum fuel on the boilers, after five years' experience, appears to be less destructive than when firing with anthracite, which is particularly destructive to the fire-boxes and tube-ends. The author states that the petroleum flame produces in reality no more detrimental effect on the fire-box and tubes than a wood flame, owing to the protection afforded to the more important parts by the fire-brick lining; moreover, petroleum refuse con ains no sulphur, which is so prevalent in all coals, and so injurions to the metal of the fire-box and tubes. The evaporative value of petroleum refuse appears to be very high. With an effective steam pressure of 125 pounds per square inch, the highest evaporative duty of the fuel in the author's locomotives has been 14 pounds of water per pound of fuel, in comparison with the theoretical evaporative value of 17.1 pounds. The actual efficiency of the fuel is therefore nearly 82 per cent., the tables giving an evaporation, under the same conditions, for good English coal, of $12^{\cdot} 16$ pounds of water.

Mr. Urquhart's paper will be read with great interest by those following his example in using various oils and tar as a fuel for locomotives and stationary boilers. Provided a cheap source of fuel in the form of petroleum refuse or oil can be relied upon, the many reasons for raising steam in this way are obvious, to say nothing of the possibility of the machinery being kept free from all the dirt necessitated by the use of coal on a locomotive.

The object of the paper on compound locomotives, by Mr. R. Herbert Lapage, is to furnish an account of some recent practice in designing and working two-cylinder compound locomotives. The advantages of compounding - that is, expanding the steam in more than one cylinder-is due to the difference of temperature between the boiler steam and the exhaust being distributed over two cylinders, with the important result that there is not so much difference as in the ordinary locomotive between the temperature at the beginning and that at the end of the stroke in each cylinder; consequently there is less initial condencation and less re-evaporation of condensed steam, and a more uniform pressure on the pistons throughout the stroke; and owing to the more constant and even pressure on the pistons, the turning moments about the driving axle are more uniform, giving less sudden strains to the machinery generally, thereby increasing the life of the machine. The fact that so little attention has until recently been paid to the compounding of locomotives appears to be owing to there having hitherto been considerable complication of parts, in connection both with obtaining a simple device for starting the engine and of equalizing the power developed in the high and low pressure cylinders. These objections have now been thoroughly overcome in what is known as the Worsdell and Von Borries system, in which the two cylinder compound locomotive has been brought to a high pitch of efficiency. The autbor of the paper describes a six-wheel-coupled goods engine which was sent out in 1886 to the Entre-Rios Governinent Railway, having been built by Messrs. Dubs and Co., Glasgow. This engine was built on the compound principle, after investigating the excellent results obtained by the WorsdeIl and Von Lorries system. The dimensions of the cylinders are-high pressure, 16 inches diameter; low pressure, 23 inches; both cylinders having a stroke of 24 inches; the working pressure being 175 pounds per square inch ; diameter of driving wheels 3 feet 9 inches. The total weight in working order is 37 tons, probably having about 30 tons useful weight for adhesion; the cut-off of the valves in ordinary running being in the high pressure cylinder 40 per cent., and in the low pressure 50 per cent. Various trial trips were made with this compound on the Caledonian Railway, the work dore without doubt showing the power and efficiency of the engine. In the locality where this engine is working coal costs at least $£ 2$ a ton; presuming an ordinary engine runs 30,000 miles a year at 25 pounds of coal per mile, it will have burnt 335 tons, which, at $f_{2} 2$ per ton, costs $£ 670$. The coinpound, effecting a saving of about 20 per cent., will accordingly save $\mathrm{I}_{3} 34$ in a year. It is found that a compound locomotive of less weight can haul as heavy a train at the same specd as an ordinary engine, provided the adhesion is sufficient, with the economy of from $14 \frac{1}{2}$ to 20 per cent., and as the cost of the compound is no greater than such an engine, the 20 per cent. or $£$ r 34 per year saved is a net saving to the engine. Compound express locomotives working the heaviest service, which run about 3000 miles per month, are found to do some ${ }_{5} 5$ per cent. more mileage between shop repairs than the ordinary engines of the same size and class.

The fact that two important papers should have been read before the Institutions of Civil and Mechanical Engineers respectively points to the conclusion that the compound locomotive has out-grown the experimental stage. Mr. Lapage says nothing in his paper about the "Webb" system, and probably this is a sign of the "survival of the fittest." The Worsdell engine requires little, if any, alteration in the primary parts of an ordinary engine. The number of working parts is not increased, and the strains set up in the engine are more uniform and less intense than in the ordinary engine, less steam is used, and therefore the boiler is not worked so hard-in fact, everything in connection with the working of these engines points to less general wear and tear of parts, and therefore longer life to the machine.

The last paper on the list, on the latest development of roller flour milling, by Mr. Henry Simon, dea's with the extraordinary revolution which, during the last ten years, has been in progress in the manufacture of flour by the substitution of the roller system for the ancient method of grinding by stones; and the object of the present paper is to give further information about the subsequent development of roller flour-milling as carried out by the author. The completeness of the revolution that has taken place is exemplified by the fact that practically, in less than ten years, the machinery and methods of corn milling have been radically and entirely altered at the cost of an immense amourt of capital. The millstone, dating from prehistoric times, has been almost entirely discarded, and the miller has been constrained to unlearn the old methods, and take up one entirely new, based upon very different principles. The first complete roller-mill, without the use of stones, in England, was built by the author in 1878 for Mr. Arthur McDougall, of Mancliester, and in Ireland for Messrs. E. Shackleton and Sons in 1879 ; the first automatic roller flourmill in England in $\mathbf{1} 88 \mathrm{r}$ for Messrs. F. A. Frost and Sons, Chester. The total number of complete mills, or important reconstructions of old mills, executed by the author since 1878 amcunts to considerably more than 200 , varying in cost for machinery, exclusive of motive power, buildings, \&c., from $£$ rooo to $£ 40,000$ for each mill.

As it is nearly impossible to give our readers an adequate description of this class of machinery without diagrams, we do not attempt the task, but recommend Mr. Simon's very interesting paper to the careful perusal of all practical millers.

\section{NOTE ON THE ACTION OF ACIDS UPON}

\section{ULTRAMARINE.}

$A^{\mathrm{T}}$ the Birmingham meeting of the British Association in September 1886, I read a short paper "On the Fading of Water-colous." This was published in the Chemical News, vol, liv.

Observation and experiments had led me to the conclusion that water-colour drawings in which ultramarine was mixed with reds for the representation of purple and gray tints such as are seen when viewing distant mountains, the shadows of clouds, and other luminous shadows, the colours are liable to suffer from the action of acids such as might be found in the drawingpaper, or in the damp atmosphere of towns where much coal is burnt. The general opinion of artists is one which I believe does not coincide with this view. The same series of experiments had shown that under ordinary circumstances indigo was a colour of great stability compared with many other pigments, and this again was in conflict with the experience of artists. It is not impossible to explain how we have arrived at such different views, and though it would be inconvenient to enter into an explanation in full, it may be considered as within the scope of this paper to record the fact that the colours were washed upon the best drawing-paper, dried in a subdued light, and not exposed to the conjoint action of damp and sunlight.

The matter in hand is the question of the stability of ultramarine in presence of acils. In an old work by M. Constant de Massoul, translated into English in I8I2, entitled "A Treatise on the Art of Painting and the Composition of Colours," a short 
account of ultramarine is given as follows :-_" The basis of this colour is Lapis Lazuli. This, added to the long and tedious operation of extracting the Blue, makes this colour very dear. In order to prove the goodness of Lapis Lazuli, make it red hot upon a plate of iron; and then throw it immediately into strong white Vinegar. If it loses its colour, it is of an inferior quality. You may likewise form a judgement by its weight, the real Ultramarine being much heavier than the false."

It is stated that the stone comes from Asia, where it is found on the frontiers of Tartary, China, and also from America. Having drawn my conclusions as to the behaviour of ultramarine with acids, from the preparations sold for this pigment, it seemed desirable that the behaviour of the mineral should be studied by itself, and likewise that of the artificial preparation. This latter, I am aware, is variable ; some of it is more easily decomposed by acids than other samples, the 'difference being occasioned by the greater amount of silica in the latter.

I applied to Mr. Gregory, of 88 Charlotte Street, Fitzroy Square, for as many different specimens of lapis lazuli and minerals resembling it as were at his disposal. They consisted of a specimen from Chili, two from Persia of magnificent colour, three from Siberia, Trans-Baikal, and a specimen of a blue mineral often mistaken for lapis lazuli called slaucolite. This also occurs in the Trans-Baikal district.

These specimens were chipped, where fragments of a fine blue colour were to be seen, and the pieces were ground in an agate mortar to an impalpable powder.

A specimen of each was placed in the hollow of a white earthenware colour palette, and moistened with sulphurous acid. All the specimens of lapis lazuli were attacked, and in nearly every case completely decolorized. Where the blue colour was not quite destroyed, the powder was examined with a powerful lens, and it was seen that blue particles remained which had not been sufficiently finely powdered. Several minute lumps of the colour were noticed to be etched by the acid, showing white spots here and there. Hence the fineness of the powder has much influence on the facility with which the mineral is attacked. This is usual with all mineral substances.

It was next considered of interest to ascertair whether lapis lazuli will stand the test applied to it by Constant de Massoul, and therefore some of the powdered mineral was made red-hot and thrown into dilute acetic acid ; after waiting for five minutes, the blue colour was not appreciably diminished, and it is to be presumed that its nature would thus be satisfactorily demonstrated. Under these circumstances, however, the colour is in considerable quantity, and though some of it may be acted on, yet it is not al destroyed, neither is the tint altered. But in the previous experiments, the powder was much finer and in a thin layer, and though there was a slight action immediately, yet it was about an hour before the colour was completely destroyed. The specimens did not all behave exactly in the same way: some were destroyed more readily than others, especially those from Chil and from Persia.

It does not appear, therefore, that my statement concerning the use of ultramarine as a pigment upon drawing-paper requires modification. A wash of bluish-gray, obtained by mixing light red with ultramarine, was handed round at the Birmingham meeting, one-half of which was shown to be of a foxy red tint after treatment with sulphurous acid. This is, of course, beside the question as to whether ultramarine is largely used for gray tints in the form of water-colour by artists.

Touching the mineral glaucolite, its composition, according to the analysis of G. von Rath, quoted in Dana's "Mineralogy," is the following : silica 47.49 , alumina $27 \cdot 57$, ferric oxide $I^{\cdot} \cdot 54$, magnesia $0^{\circ} 47$, lime $17 \cdot 16$, soda 4.71 , potash 0.58 , and water 0.48 per cent. It is quite nnacted upon by the acids which decompose lapis lazuli. It is highly improbable that it has ever been used as a pigment, because in the form of powder its colour is poor.

W. N. HartLEy.

\section{LONDON ANCIENT AND MODERN, FROM A} SANITARY POINT OF VIE $W^{1}$

$D$ R. POORE began by reminding his hearers that the mere age of London was one of the reasons why it became unwholesome. Roman London was buried deeply amongst rubbish of all kinds, much of which was putrescible, and, therefore, a source of danger in the soil.

${ }^{1}$ Abstract of a Lecture delivered by Dr. G. V. Poore at the Sanitary Institute on Thursday, January 24 .
Ancient London was well placed and magnificently supplied with water, for in addition to the Thames there were many streams, such as Westbourne, Tybourne, the Fleet River, Walbrook, and Langbourne, which originally were sources of pure water. All these brooks, however, had become disgracefully fouled, and for very shame had been covered over. One great drawback to the site of London was the proximity of marshy land on every side except the north-west, and formerly from this cause malarial fever and dysentery were great causes of the high death.rate.

In mediæval London, and even down to the eighteenth century, the houses were not so closely packed as they are now. Reference to Aggas's map (time of Elizabeth) would show that there was a great deal of garden ground within the City, and on comparing this map with Newcourt's map (Charles II.) it was evident that just before the Plague and the Fire the crowding of houses had become very much greater than it was in the time of the Tudor monarchs, who discouraged building near or in London.

Parker's map (I 720 ) would also show that after the Fire the houses were not so closely packed as in the days of the Stuarts, for in this map a surprising amount of garden ground is visible within the walls. At this time also Moorfields was not built upon, and remained as a playground and air space as it had done for centuries previously. That mediæval London was very unhealthy, a perfect fever den, there could be no doubt. The Black Death in I349, and the Sweating Sickness two centuries later, were times of great mortality which struck the popular mind, but it was not till 1593, when bills of mortality were first introduced, that we began to have any certain knowledge of the amount or the kind of disease prevalent. There was jeason to think, however, that in the eighteenth century (after the Fire and the Great Plague) the deaths exceeded the births by about 600,000 in the hundred years.

The fatal diseases were mainly fevers-malarial fever, smallpox, typhus, measles, and (latterly) whooping-cough. The causes of the enormous mortality of mediæval London were due-(x) To the marshy undrained soil, fouled with refuse of every kind. (2) The filthy state of the unpaved city, and a perfectly swinish condition of the houses of the lower orders. (3) The ill-nourished and drunken condition of the masses, among whom a taint of scurvy was very common. (4) The condition of superstition and brutality (as evidenced by the punishments and the 'pastimes) which made any measures of public health impracticable. (5) The management of epidemics was bad, with a total neglect to separate the sick from the sound; and, finally, the medical faculty were scarcely less ignorant and superstitious than their patients.

Turning to modern London, the lecturer said there had been a great and manifest improvement; but when we looked at the low figure which is called the London death-rate, several things must be taken into consideration, $e \cdot g$. (I) The London of the Registrar-General included large districts such as Lewisham, Wandsworth, Fulham, \&c., which, in great part, were scarcely urban in character; and these being occupied largely by well-todo persons, lowered the average death-rate for the whole city. (2) London being a city in which wealthy people abounded, its death-rate must not, in fairness, be compared to a city packed with undiluted operatives. (3) The mobility of the population was so great that this fact must vitiate our statistics, and it was to be remembered that nothing quickened the departure of an individual from London more than ill-health. (4) The age distribution in London was very abnormal. It was largely recruited by selected adults from the country, and there was a great deficit in the extreme ages among which (the very young and very old) death-rate is always highest. (5) Again, the diminishing birth-rate (that for 1887 was 2.8 below the average of the previous ten years) very greatly diminished the death-rate in a city where 158 children out of every 1000 born die before they are one year old.

It was difficult to believe that Londers were very robust when more than 25 per cent. of them had recourse to the public hospitals in the course of the year.

The cause of the diminished death-rate (which was very considerably reduced after every allowance had been made) was due -(I) To the increase of knowledge, not only among doctors, but amongst the people generally, for we must remember that "self-preservation is the first law of Nature." (2) Vaccination, and the modern plan of treating infectious diseases by the prompt separation of the patients, had done a great deal ; the total absence 